\title{
UAS Education at the French Civil Aviation University
}

\author{
Jim Sharples \\ ENAC, Université de Toulouse \\ Toulouse, France \\ jim.sharples@enac.fr
}

\author{
Gautier Hattenberger \\ ENAC, Université de Toulouse \\ Toulouse, France \\ gautier.hattenberger@enac.fr
}

\begin{abstract}
The French Civil Aviation University's (ENAC, École Nationale de l'Aviation Civile) main objectives are to train personnel specialised in air transport, and to help these specialists adapt to civil aviation's evolution, such as the advent of Unmanned Air Systems (UAS) in our skies. This paper shows that in ENAC, education in UAS is carried out in the same way than education in manned aviation topics. The training is divided in main subjects, which are then allocated to each student population according to their future roles: engineers, air traffic controllers, technicians, etc. Teaching is led by skilled personnel and backed up by modern facilities and equipment. This allows ENAC to provide a competent, specialised work force, ready to work on all aspects of the emerging and disruptive UAS-based operations.
\end{abstract}

Index Terms-Unmanned Air Systems (UAS), Education, University

\section{INTRODUCTION}

Many universities around the world do provide education on Unmanned Air Systems (UAS) or Unmanned Systems in general. This is for instance the case at Cranfield (UK), TU Delft (The Netherlands), Embry-Riddle Aeronautical University (USA) or RMIT (Australia), among others. Most of these education programs are focusing on Engineering aspects. Thus, UAS can be used to teach e.g. flight control [1] or data fusion [2]. Drones can also be seen as a tool, therefore some of the teaching focuses on the end-user application, such as cartography [3], or meteorological instrumentation integration as done by the French Meteorological Office [4].

This paper shows how skills and knowledge in UAS are instilled into the French Civil Aviation University's (ENAC, École Nationale de l'Aviation Civile ${ }^{1}$ diverse student populations. The term "UAS" is here used to encompass the airborne vehicle (all sizes are considered), the command and control links with the ground station and/or remote pilot, and the ground station and/or remote pilot. UAS can be used for an ever-wider range of applications, some of which will be highlighted in this paper.

ENAC was created post-World War II as a training school for the French Civil Aviation Authority's (CAA, or DGAC in French) civil servants. It thus trained engineers, managers, air

\footnotetext{
Work for this paper was supported by Groupe ADP and Sopra Steria
}

${ }^{1} \mathrm{http}: / / \mathrm{www} . e n a c . f r / e n$ traffic controllers and technicians. Since that time, ENAC has kept its original function but also grown to now train a wide variety of professionals in the field of civil aviation. It has also developed a strong research program, whose results are then integrated within the French CAA, but also worldwide.

One of ENAC's overarching aims is to help the different categories of professionals it trains to adapt to civil aviation's evolution.

ENAC divides its training in civil aviation in three main pillars: management (rules and regulations, Air Traffic Control); system engineering; and operations (of airlines, airports, ground systems). These competencies are then allocated to the student populations according to their future roles and diplomas, as described in the subsections below, and in figure 1 .

For each of the student groups, we will detail how we craft UAS education tailored to their specific needs, thanks to the competencies of the teaching staff and to appropriate methods and tools.

\section{ENAC GRADUATE ENGINEER (IENAC)}

\section{A. Grade and Roles}

The French degree Diplôme d'Ingénieur is equivalent to a Master of Science (MSc) in Europe. These engineers will either serve as civil servants ( $10 \%$ of a given year group) or work in the industry. Those that are civil servants can be involved in the definition, writing and/or application of the rules and regulations that govern civil aviation. Those that work for the industry will mostly be employed as Systems Engineers or experts in Aviation Operations.

\section{B. UAS education for IENAC}

1) Rules and Regulations: UAS rules and regulations are a relatively new topic (the first UAS laws were introduced in France in 2012) and an ongoing effort. In France, the CAA is the regulatory body in charge. It therefore stands to reason that the IENAC graduate engineers called to become civil servants within the CAA are taught this subject. But rules and regulations are just one of the pillars supporting UAS operations and market growth. A UAS traffic management system must also be built. Of course, the development of such a system intertwines deeply with the deployment of 


\begin{tabular}{|c|c|c|c|c|c|c|c|}
\hline \multirow{2}{*}{\begin{tabular}{|c|} 
Degree \\
Years
\end{tabular}} & \multirow{2}{*}{$\begin{array}{c}\text { Bac* } \\
0\end{array}$} & \multicolumn{3}{|c|}{ Bachelor } & \multicolumn{2}{|c|}{ Master } & \multirow{2}{*}{$\begin{array}{c}\text { Advanced } \\
\text { Master } \\
6\end{array}$} \\
\hline & & 1 & 2 & 3 & 4 & 5 & \\
\hline & & \multicolumn{5}{|c|}{ IENAC } & \\
\hline & & & & \multicolumn{3}{|c|}{ ATSEP } & \\
\hline & & & & \multicolumn{3}{|c|}{$\begin{array}{c}\text { ATCo } \\
\text { (French CAA) }\end{array}$} & \\
\hline & & \multicolumn{3}{|c|}{$T S A$} & & & \\
\hline & & $\begin{array}{l}\text { ATCO** } \\
\text { (MUAC) }\end{array}$ & & & & & \\
\hline & & & & & & & $\begin{array}{c}\text { UAS Services } \\
\text { and } \\
\text { Management }\end{array}$ \\
\hline \multicolumn{2}{|c|}{ *Baccalauréat } & \multicolumn{6}{|c|}{ **only the time spent in ENAC is represented } \\
\hline
\end{tabular}

Fig. 1. ENAC courses.

rules and regulations, so both topics are always presented together. Education in this topic comes by way of talks (1 or 2 hours) and lectures ( 2 to 4 hours) delivered by experts in French and European UAS Regulations. These experts in the field work either directly for the French CAA, or for the ENAC-Groupe ADP-Sopra Steria Research Chair on Drone System $2^{2}$ (part of ENAC's UAS Research Program). Some of them are also certified drone pilots, which allows them to outline the regulations from an operational standpoint. Additionally, ENAC's own open-source hardware and software for UAS enables the teachers to showcase a typical UAS architecture, and both indoor and outdoor flights are carried out to demonstrate UAS capabilities (see also section II-B2).

2) UAS Design for IENAC: The teaching of system design from the UAS point of view has two purposes: firstly, provide knowledge and skills to future engineers targeting employment in the drone market; secondly, bolster education by giving students challenging and appealing practical projects.

The teaching methods used span a wide range of formats: talks ( 1 or 2 hours) on a specific topic, classic lectures (4 to 10 hours per topic) to provide more in-depth knowledge, practical and lab work (up to 20 hours) to gain practical skills and finally group projects (up to 80 hours) to fuse and apply to concrete problems the knowledge gained. IENAC students can thus benefit from a dedicated program of 80 hours to build foundation knowledge and, for those who wish and are selected, a research-oriented project of 80 hours. The selection process takes into account student motivation and academic results.

The knowledge imparted relies on several technical domains that are already covered in depth by the school's IENAC program. These include:

- system engineering,

${ }^{2} \mathrm{http} / / / \mathrm{drone}$-chair.enac.fr/
- control of dynamic systems,

- communication and control links,

- embedded systems and programming,

- conceptual design,

- payload and instrumentation.

To provide this broad spectrum of teaching, ENAC can rely on the professors and researchers of its UAS Research Program, who have been developing open-source hardware and software for UAS called Paparazz ${ }^{3}$ since 2005 [5]. This system is of course deeply embedded in the lectures and practical projects and is one of their main pillars. In addition to that, an indoor flight arena is available on the campus. It has an effective volume of $11 \times 9 \times 9$ meters and is equipped with an Optitrach $4^{4}$ camera-based positioning system, that enables 3D positioning with millimetric precision. This facility allows for safe flights and demonstrations. It is well suited to student projects, as a basic training of 2 hours is enough for them to become autonomous and fully use the system unsupervised. Figure 2 shows students testing a dedicated human-machine interface design for a system engineering project.

An example of one of the research-oriented projects, involving four students for 80 hours, is the study of autonomous landing of a fixed-wing aircraft in a net using ground-based ranging modules. Their tasks included writing up a state of the art report on the topic, leading a theoretical study of the expected positioning accuracy, and integrating the different components on a test aircraft as well as analysing the flight test results. The experimental plane, partially assembled by the students, can be seen in figure 3 This work served as the preliminary study for a paper published in a UAS-dedicated conference [6].

\footnotetext{
${ }^{3}$ http://paparazziuav.org

${ }^{4} \mathrm{http} / / /$ www.optitrack.com
} 


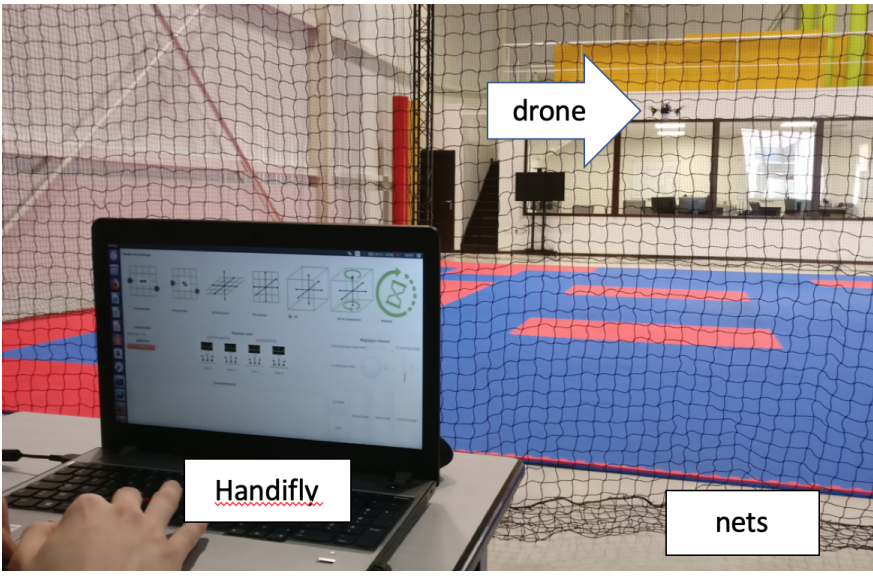

Fig. 2. Human-Machine Interface student project inside the flight arena.

\section{Air Traffic Safety Electronics Personnel} (ATSEP)

\section{A. Grade and Roles}

Air navigation and air traffic management rely on safetycritical ground infrastructure: radars, radio navigation beacons, Control Tower IT networks, etc. ATSEP are responsible for this infrastructure: from assessing its needs and following industrial developments, to deploying, maintaining and upgrading its components, whilst also contributing to the regulations governing it. In France, ATSEP are civil servants, and they are trained exclusively at ENAC. Their diploma is equivalent to a Master's degree.

\section{B. UAS education for ATSEP}

1) UAS Design for ATSEP: ATSEP can be tasked with conducting inspection missions. For some of these operations, UAS are coming to the fore as potentially cost and timecutting tools, generating exhaustive data sets that complement traditional methods. For these inspection missions, ATSEP need to be competent in UAS design, particularly in the payload and instrumentation topics. Practical projects of 80 hours are proposed to groups of two students each, where the aim is to design and implement a payload for a designated mission. The UAS is provided by the UAS Research Program, along with the constraints for the payload (in terms of size, weight and power). For these topics, since the instrumentation can be quite specific, the ATSEP's teachers also take part in the projects alongside staff from the UAS Research Program.

2) UAS-based operations: For an inspection mission, the drone must of course be equipped for the task at hand (see Section [III-B1], but the setup of the operation must also be carefully planned. This is where training in UAS-based operations fits in. As of now, it is limited to ATSEP who carry out specific projects on drone instrumentation (as mentioned in Section III-B1, and it encompasses most of the topics detailed in Section III-B1 and IV-B. These topics are tailored to fit a specific mission's requirements and are delivered by an

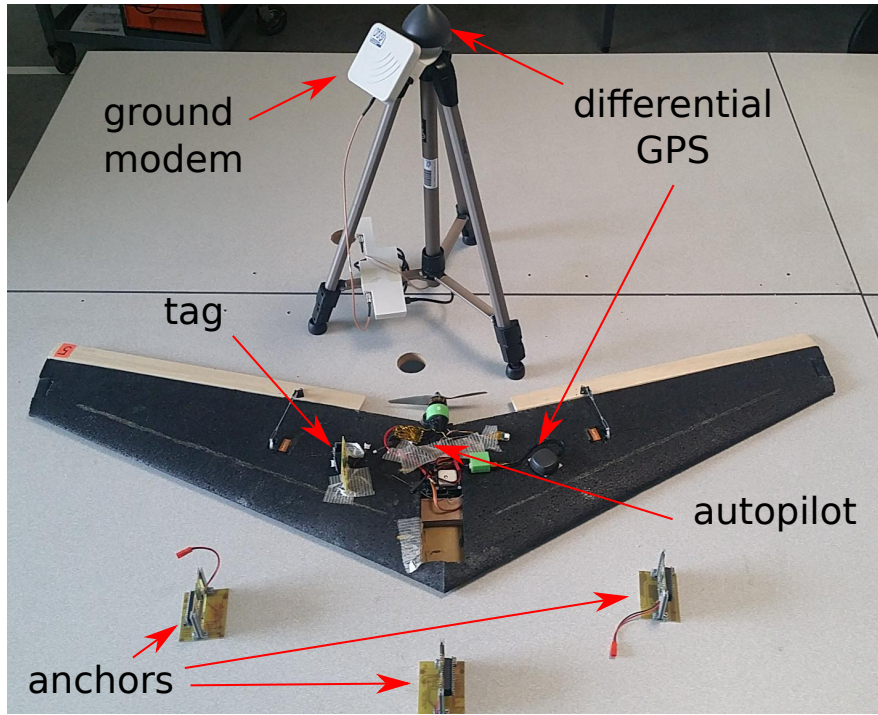

Fig. 3. Experimental setup for a student project.

engineer from the ENAC Research Chair on Drone Systems, who is also a certified drone pilot.

\section{Air Traffic Controllers (ATCos)}

\section{A. Grade and Roles}

ATCos manage the airspace and the air traffic. Their aims are: to prevent collisions in the air and on the ground; to accelerate and organise air traffic; to provide information vital for maintaining flight safety; to take part in search-and-rescue efforts. In France, ATCos are civil servants, and they are trained exclusively at ENAC. Their diploma is equivalent to a Master's degree. ENAC also partly trains ATCos working for EUROCONTROL's Maastricht Upper Area Control Centre (MUAC).

\section{B. UAS education for ATCos}

In France, leisure drones are constrained by law to fly in segregated airspaces, where no other manned flights take place (under $500 \mathrm{ft}$ above ground level and out of cities and airports). However, registered professional drones can be authorised, by the relevant bodies, to fly close to airports. Among the relevant bodies, Air Traffic Control can be called for. This means that air traffic controllers benefit from being educated in these very new systems: how they are operated, what are typical size weight and power and trajectory characteristics, how they are regulated, tracked, managed. Currently at ENAC, only ATCos for EUROCONTROL's Maastricht Upper Area Control Centre are educated in UAS by way of a two-hour lecture that brushes on all the topics detailed in the previous sentence. This lecture is delivered by an expert from the ENAC Research Chair on Drone Systems, who is also a certified drone pilot. The lecture encompasses a flight demonstration in the school's indoor flight arena based on ENAC's own open-source UAS. Additionally, members of ENAC's UAS Research Program can be called upon as experts for the assessment of ATCos' (either for the French CAA or for Maastricht) school projects. 


\section{Advanced Technician Degree in AViation (TSA)}

\section{A. Grade and Roles}

These technicians (TSAs in French) can either serve as civil servants or work in the industry. Civil servants are involved in a wide array of tasks for the French CAA: air traffic control on small aerodromes, defining aircraft arrival and departure procedures, airport inspection and surveillance, supporting the department in charge of incident/accident investigations, etc. In the private sector, TSAs can work for airport management companies, airlines, aircraft manufacturers. They lead tasks such as runway use optimisation or airworthiness checks.

\section{B. UAS education for TSAs}

Some TSAs might control air traffic in small aerodromes once they graduate; so they benefit from being educated in the same UAS topics as the ATCOs. Additionally, TSAs might be tasked with conducting inspection missions; so, like the ATSEPs, they benefit from being educated in UAS design and operations. Currently, this UAS education for TSAs is carried out by members of ENAC's UAS Research Program, who assist students with ongoing school projects, and can be called upon as experts for the assessment of said school projects.

\section{UAS SERVICES AND MANAGEMENT ADVANCED MASTER}

\section{A. Grade and Roles}

The French Advanced Master is a one-year course available to students that already hold a MSc. It is a means to specialise in a given topic. It is not open to ATSEP nor ATCos. ENAC developed this Advanced Master to meet UAS operators, manufacturers and air transport regulatory bodies' demand in high-level experts. Graduates are not civil servants, and can work as auditors, regulatory officers, research managers, business developers, designers, test managers, operations managers, data processing supervisors; in sectors such as air transport, audio-visual media, agriculture, energy production and distribution, etc.

\section{B. UAS education for Advanced Master}

ENAC is the first aeronautical university in Europe to open an Advanced Master on UAS management, applications and services. The course is divided in three blocks:

- Strategy (regulatory framework and UAS market analysis),

- Technical Aspects (all the basic knowledge to understand UAS design from an engineering point of view),

- Field Operations (pilot training, vehicle maintenance, mission setup and roll-out).

During the first 6 months, the knowledge is imparted thanks to talks, lectures and case studies, delivered by a wide range of experts: members of ENAC's UAS Research Program, professors in air transport economics (one of ENAC's specialities), and professionals of the field (drone operators and/or manufacturers). Also, during these 6 months, a practical project runs parallel to the classroom lectures. The second block of 6 months is an internship in a company of the field.

\section{CONCLUSION}

In this paper, we have explained how ENAC provides the personnel needed by manned air transport: engineers, air traffic controllers, technicians, etc. But manned aviation is currently facing a newcomer in its airspaces: Unmanned Air Systems. In order to increase the competencies of the professionals it trains, and help them adapt to civil aviation's evolution, ENAC also provides education in UAS. This training is modelled on the training given in manned aviation topics. The UAS subject is divided in three main categories: management, system design, and operations, which are then allocated to the different student populations according to their future roles and responsibilities. At the core of this teaching stands the UAS Research Program, its staff and its equipment, and its open source hardware and software platforms. These resources are enhanced by personnel with complementary skills and knowledge: in instrumentation, air transport economics, UAS operations, etc. This allows ENAC to provide a competent, specialised work force, ready to work on all aspects of the emerging and disruptive UAS-based operations.

\section{ACKNOWLEDGMENT}

The authors would like to thank Yannick Jestin (Head of UAS Research Program), and all the ENAC teachers involved in the training courses in UAS. The authors would also like to thank researchers Torbjørn Cunis and Murat Bronz for reviewing this paper.

\section{REFERENCES}

[1] Y. Zhang, "Using cutting-edge unmanned aerial vehicles ( uavs ) technology for flight controls courses teaching," in Proceedings of EDULEARN11 Conference, 2011.

[2] J. S. G. Guerrero, A. F. C. Gonzlez, J. I. H. Vega, and L. A. N. Tovar, "Instrumentation of an array of ultrasonic sensors and data processing for unmanned aerial vehicle (uav) for teaching the application of the kalman filter," Procedia Computer Science, vol. 75, pp. 375 - 380, 2015, 2015 International Conference Virtual and Augmented Reality in Education. [Online]. Available: http://www.sciencedirect.com/science/article/pii/S1877050915037217

[3] R. Al-Tahir, "Integrating uav into geomatics curriculum," ISPRS International Archives of the Photogrammetry, Remote Sensing and Spatial Information Sciences, vol. XL-1/W4, pp. 387-390, 2015. [Online]. Available: https://www.int-arch-photogramm-remote-sens-spatial-inf-sci. net/XL-1-W4/387/2015/

[4] G. Cayez, G. Hattenberger, M. Gorraz, A. Bustico, and G. Roberts, "Active teaching and learning of the use of RPA in meteorology," ISARRA 2018, International Society for Atmospheric Research using Remotely Piloted Aircraft, Jul. 2018, poster. [Online]. Available: https://hal-enac.archives-ouvertes.fr/hal-02191714

[5] G. Hattenberger, M. Bronz, and M. Gorraz, "Using the Paparazzi UAV System for Scientific Research," in IMAV 2014, International Micro Air Vehicle Conference and Competition 2014, Delft, Netherlands, Aug. 2014, pp. pp 247-252. [Online]. Available: https://hal-enac. archives-ouvertes.fr/hal-01059642

[6] G. Hattenberger, "Precision Landing for Fixed-wing UAV using UltraWide-Band Ranging," in IMAV 2018, International Micro Air Vehicles, Conferences and Competitions, Melbourne, Australia, Nov. 2018. [Online]. Available: https://hal-enac.archives-ouvertes.fr/hal-01936955 